\title{
HIV: A journey just begun
}

\author{
Lindsay E Nicolle MD FRCP, Editor-in-Chief
}

$\mathrm{I}_{\mathrm{w}}^{\mathrm{t}}$ $t$ is a quarter century since the first North American cases of what was to be named the acquired immunodeficiency syndrome (AIDS) occurred (1). These first cases were recognized only in retrospect - the disease was present for two or three years before the description in 1981 of gay men in Los Angeles presenting with Pneumocystis carinii pneumonia (2). Subsequent reports, from North America and elsewhere, described an escalating frequency of unusual infections and tumours suggestive of profound immunodeficiency occuring in gay men, sexual partners of AIDS patients, hemophiliacs, persons who had received blood transfusions and children. The subsequent relentless global dissemination and pervasive socioeconomic influence of this disease was certainly not appreciated in the first scientific presentations of clinical and epidemiological features at meetings in the fall of 1981. Most individuals currently in medical school in Canada have never experienced a world without AIDS. The virus is now a permanent fixture in our human landscape.

Looking back on the AIDS progression from a 2004 perspective, one view shows the triumphs of science and medicine in responding to this novel human virus. The basic science foundation underpinning medicine proved its value with the rapid identification of the causative agent, with some unexpected entertainment in watching the political maneuvering of the National Institutes of Health, Pasteur Institute, their scientists, and subsequent revelations of potential malfeasance (3). The exploration of the human biology of HIV infection has also substantially advanced our knowledge of the immunology of infections and tumours. Additionally, the intense, focused program to develop effective therapies is evidence of how a combination of political will, scientific expertise and the profit imperative can rapidly find solutions for a novel problem.

A second view from our current perspective is of the societal impacts of HIV infection, beyond science and clinical care for the individual patient, in our own and other countries. The perception and management of risks attendant in blood and blood products has shifted, and safety and liability issues are now at the forefront. Senior bureaucrats and politicians have been held accountable for HIV transmission. Perceptions and practices have also changed in occupational health for health care workers and others. Universal precautions, now subsumed into routine practices, promotes optimal safety through consistent practice for all patients and all situations. Regulatory approaches now allow rapid licensing and early access to potentially effective agents. The overall impact is improved standards in many areas and benefits beyond HIV.
But a third view of the HIV landscape is one of appalling failure - failure to halt the relentless global progression of this disease and the profound societal impacts resulting from this failure. Despite the early characterization of routes of virus transmission - sexual and parenteral - effective, sustainable interventions to control the endemic spread or prevent introduction into new populations have not followed. The virus has continued to expand into initially unaffected countries. South Africa, China, Russia and India are prominent recent examples. It is estimated that 70 million people globally have been infected to date, and projections for the next decade estimate further tens of millions of new infections. In particular, in Africa the HIV infection is an apocalypse of decreased longevity, economic loss, millions of orphans and political instability. Compare this experience with a more recent new disease - severe acute respiratory syndrome (SARS). Interventions effective to prevent transmission were also recognized early, systematically applied globally, and the epidemic controlled, even without effective treatment or understanding of the biology of the virus. Yes, there are differences in transmission, incubation, presentation and other features, but the SARS experience reminds us that infectious diseases can be controlled, and underscores our failures with HIV. And now, early triumphs in prevention in some high-risk populations in North America and other developed countries are receding as rates of HIV infection increase in populations where it was previously controlled (4). How do we limit disease transmission in populations who choose to practice highrisk behaviours such as parenteral drug use and unprotected sexual activity with multiple partners? With increasing rates of HIV infection are increasing rates of 'classical' sexually transmitted diseases such as gonorrhea and syphilis, which had practically disappeared in North America (5).

The individual professional providing HIV care in North America sees a positive experience in the management of HIV infection every day. Complicating infections are successfully treated. Patients maintain high CD4 counts and low viral loads on antiretroviral therapy. Previous means of infection transmission - blood and blood products, neonatal, occupational - have virtually disappeared. But the larger national perspective is uncertain and internationally it is grim. The rarefied developed world perspective is one of optimism that a continuing progression of new antiviral therapies will improve our current therapies and consistently address resistance emergence. But the efficacy and adverse effects of very long term antiretroviral therapy remain unknown. Meanwhile, the virus continues its global expansion and increasing numbers of cases 
while personal, political, social and economic barriers compromise treatment and prevention.

The best answer to this biological catastrophe is an effective, affordable vaccine. While this is widely appreciated, and remarkable resources have been applied towards vaccine development, the combination of science, political will and the profit imperative have not led to success in vaccine development as they did for therapy. In the face of biological observations which question the feasibility of a preventive vaccine and uniformly negative human trials to date, and beyond disagreements about appropriate application of vaccine resources, this exploration must continue. And yes, costs, infrastructure and patents must also be addressed so effective antiretroviral therapy can be distributed to the larger global population. The goal is to maintain cohesive societies by keeping young adults alive and functional to raise their children and contribute to the social and economic fabric of their communities.

HIV infection is the true 'new normal'- an insidious plague which undermines national and global security. A continuing, intense commitment to prevention of disease transmission must be the foundation of all HIV programs. At a minimum, surveillance programs must be comprehensive and timely, and messages of prevention focused on individuals, high risk groups and society must be part of daily life. More intensive case finding is necessary. Controlling the current resurgence in other sexually transmitted diseases is part of the HIV prevention strategy. Perhaps incremental changes in current programs in Canada and globally may improve effectiveness of HIV prevention, but new creative and innovative approaches are clearly necessary. The current status of HIV control is not good, nor even adequate.

\section{REFERENCES}

1. Selik RM, Haverkos HW, Curran JW. Acquired immune deficiency syndrome (AIDS) trends in the United States, 1978-1982. Am J Med 1984;76:493-500.

2. Centers for Disease Control: Pneumocystis pneumonia-Los Angeles. MMWR Morb Mortal Wkly Rep 1981;30:250-2.

3. Crewdson J. Science Fictions. A Scientific Mystery, A Massive Cover-up, and the Dark Legacy of Robert Gallo. Little, Brown and Company. Boston 2002.

4. New data from the CDC confirm HIV is on the rise. Aids Alert 2004;19:15-7.

5. Erbelding E, Rompalo A. Changing epidemiology of syphilis and its persistent relationship with HIV. Curr Infect Dis Rep 2004;6:135-40. 


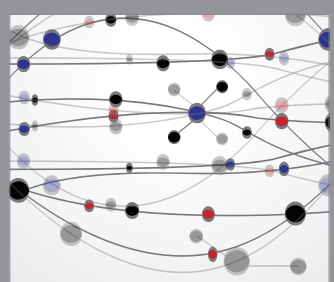

The Scientific World Journal
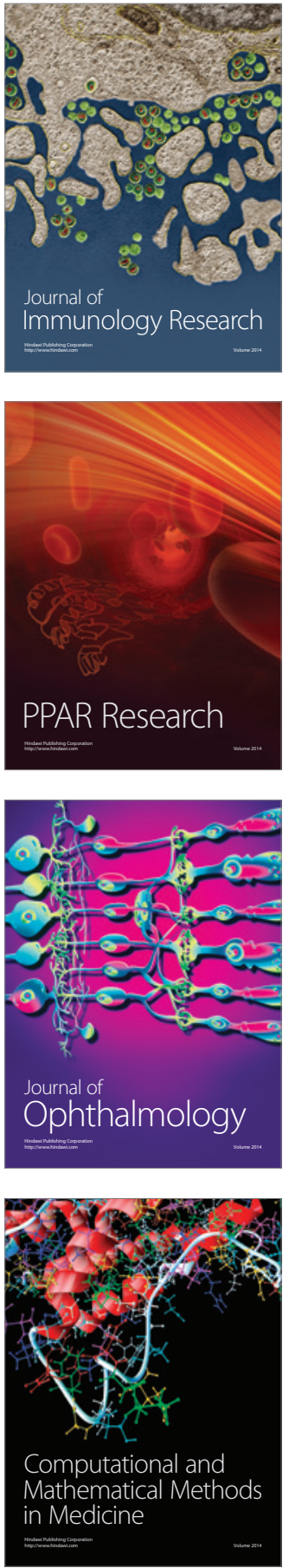

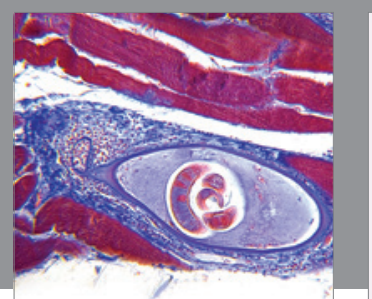

Gastroenterology Research and Practice

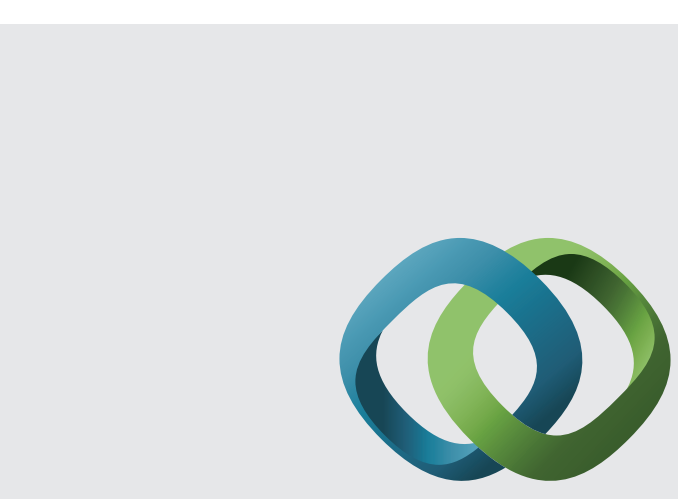

\section{Hindawi}

Submit your manuscripts at

http://www.hindawi.com
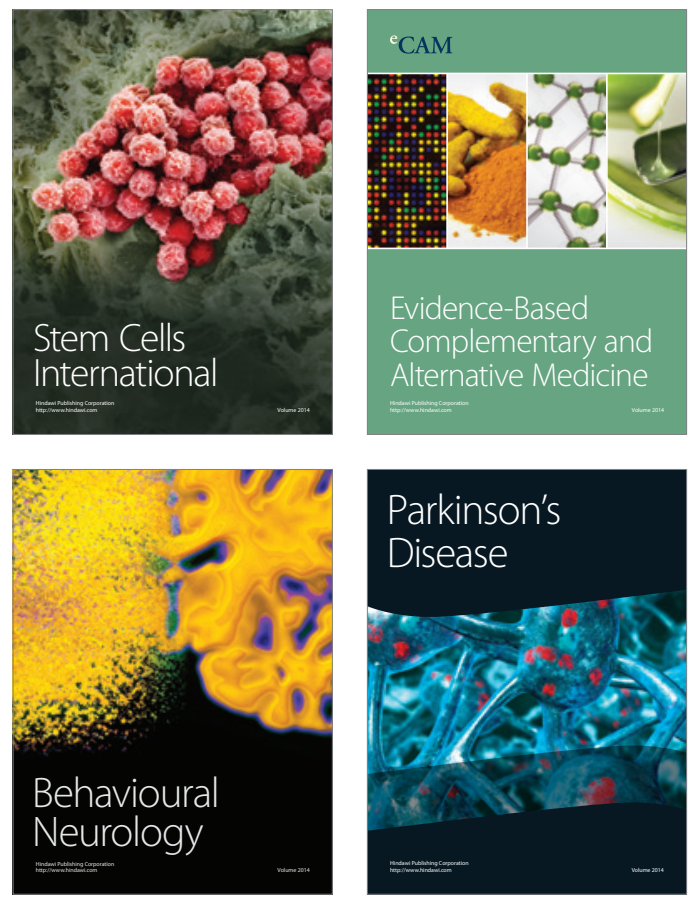
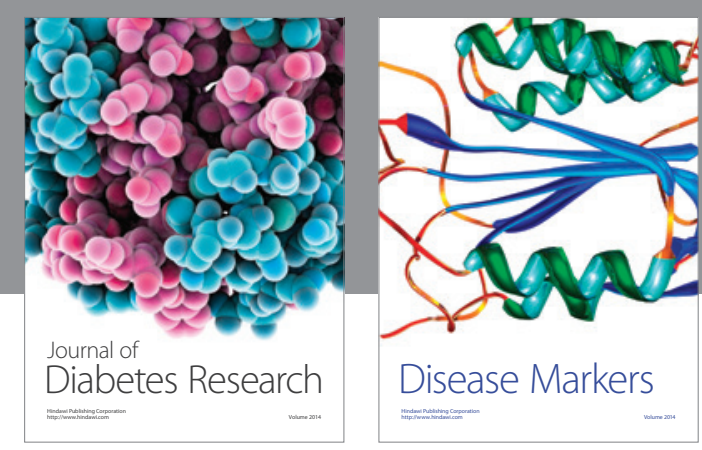

Disease Markers
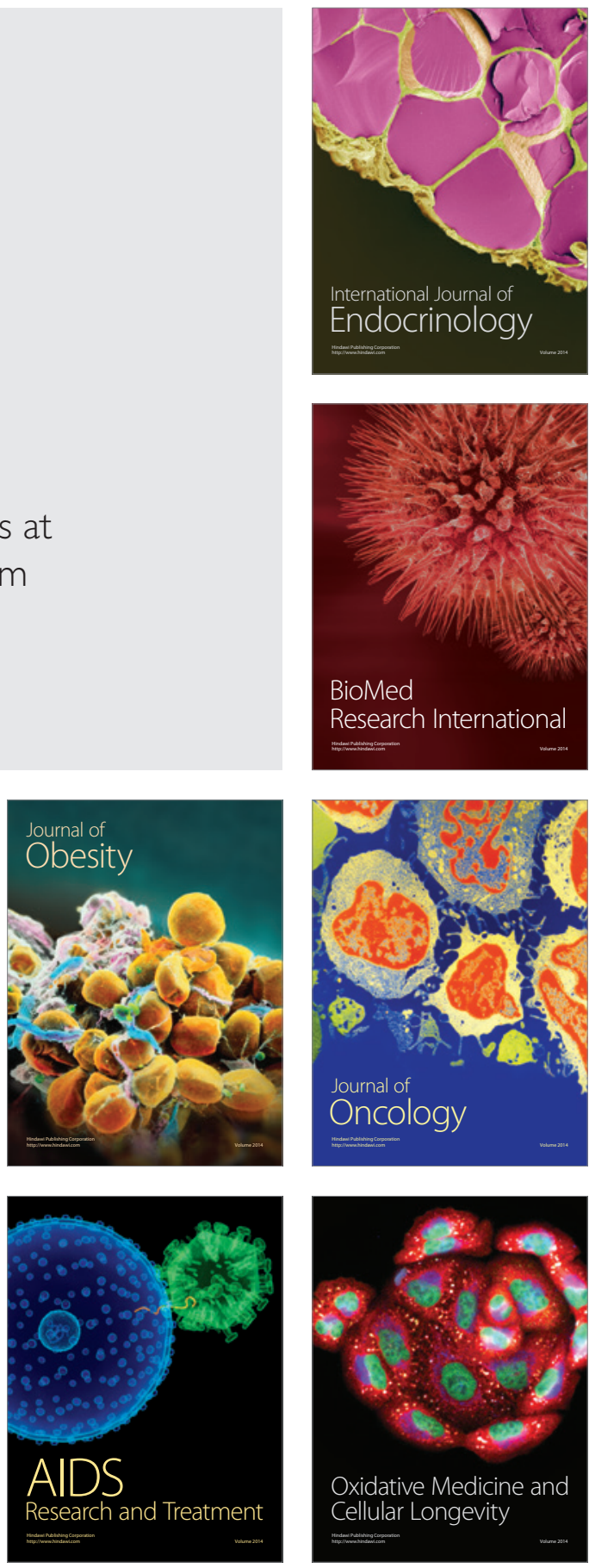